\title{
Nano-Immunodetection and Quantification of Mycobacteria in Metalworking Fluids
}

\author{
Shu-Chi Chang and Peter Adriaens* \\ Department of Civil and Environmental Engineering \\ University of Michigan \\ Ann Arbor, MI
}

\begin{abstract}
The accurate detection and enumeration of mycobacteria in metalworking fluids (MWFs) is imperative from an environmental protection and occupational health perspective. We report here on a comparison of the labeling efficiency of nano-immunomagnetic particles (NIMP) and free antibody (FAb) to detect mycobacteria in semisynthetic MWF by using both traditional visualization analysis and cluster analysisaided visualization analysis (CAAVA). The NIMP labeling method involved coating nanometer-scale magnetic particles with Protein A, and oriented conjugation of polyclonal antibodies specific to Mycobacterium spp. The FAb labeling method is modified from the traditional immunofluorescence (IF) method for more efficient detection of mycobacteria in a model MWF. The labeling efficiency of NIMP and FAb were $7.2 \pm 4.6$ and $16.3 \pm 5.5 \%$, and the specificity $85.0 \pm 6.1$ and $88.1 \pm 10.5 \%$, respectively, based on traditional visualization analysis. Based on CAAVA analysis, the labeling efficiency of NIMP and FAb increased to $12.4 \pm 1.6$ and $20.5 \pm 3.9 \%$, and the specificity to $97.8 \pm 3.2$ and $98.5 \pm 2.5 \%$, respectively. A linear relationship of FCM counts and seeded concentrations was observed over four orders of magnitude $\left(R^{2}>0.99\right)$ in pure and ternary cultures. The results strongly support the applicability of either FAb or NIMP coupled with CAAVA and flow cytometry for rapid detection and enumeration of mycobacteria in complex matrices.
\end{abstract}

Key words: nanoparticle; flow cytometry; mycobacteria; metalworking fluids; cluster analysis

\section{INTRODUCTION}

M ETALWORKING FLUIDS (MWFs) are used for cooling and lubrication in a wide range of metal-forming and -removing processes. Annual U.S. consumption of MWFs is estimated at 6 billion liters (Independent Lubricant Manufacturer Association, 2000). MWFs are categorized in four types: straight oil, soluble oil, semisyn- thetic, and synthetic fluids, of which soluble oil and semisynthetic types are most widely used (Childers, 1994). Semisynthetic MWFs, an oil-in-water emulsion, represent prolific substrates for aerobic bacterial growth (Bennett, 1972; Hill, 1977) and more than 10 hypersensitivity pneumonitis (HP) outbreaks have been linked to mycobacterial proliferation in water-based MWFs in the past decade (Muilenberg, et al., 1993; Bernstein et al.,

*Corresponding author: Room 116, EWRE Bldg., 1351 Beal Avenue, Ann Arbor, MI 48109. Phone: 734-763-8032, Fax: 734763-2275; E-mail: adriaens@umich.edu 
1995; Kreiss and Cox-Ganser, 1997; Moore et al., 2000; Weiss et al., 2001). Consequently, once mycobacteria have been detected in manufacturing operations using MWFs, unscheduled discharges of MWFs to wastewater treatment may be required, hence impacting wastewater treatment downstream and increasing downtime in metalworking processes. Aggressive formaldehyde condensate biocide-based control of microbial growth resulted in the change in bacterial flora favoring proliferation of a nontuberculous Mycobacterium and $95 \%$ of isolates, 102 of 107 isolates from 10 industrial sites, were identified to be Mycobacterium immunogenum (Wilson et al., 2001; Wallace et al., 2002). Due to these issues, M. immunogenum has emerged as a significant health hazard agent (Shelton et al., 1999; Wilson et al., 2001) in metalworking processes, and their accurate detection and quantification have become a necessity (Passman and Rossmoore, 2002).

Traditional enumeration methods for bacteria in MWFs include direct and indirect detection technologies (briefly reviewed in Chang et al., 2004). Due to the slow growth rate and aggregate-forming characteristics of mycobacteria, these approaches may either underestimate their cell density or are too time-consuming to be effectively used for process control. Recently, some molecular biological approaches have been tried, such as fluorescent in situ hybridization of peptide nucleic acid probe (Skerlos et al., 2003) and real-time polymerase chain reaction (Yadav et al., Khan and Yadav, 2004a, 2004b; Veillette et al., 2004), 16S ribosomal deoxyribonucleic acid (DNA) denaturing gradient gel electrophoresis, and deoxyribonucleic acid fluorescent in situ hybridization (van der Gast et al., 2001). Still, these methods mostly focused on identification and indirect quantification instead of on direct enumeration, and may not be readily applied to the field due to lack of disaggregating measures. These limitations necessitate the development of a rapid, sensitive, and accurate enumeration method to effectively quantify mycobacteria in MWFs.

In the past decade, flow cytometry (FCM) has been increasingly used for direct optical detection of bacteria in aquatic systems and in environmental samples with complex matrix characteristics (Porter et al., 1997; VivesRego et al., 2000; Gruden et al., 2004). FCM technology is based on optical detection of particles within a sample stream hydrodynamically focused by sheath fluid in a flow cell, where incident light is introduced by a laser source (BD-Biosciences, 2001). Particles exhibit different light-scattering characteristics due to their size, internal complexity, granularity, and fluorescence due to specific dyes. Recent reviews on FCM applications in complex environmental matrices can be found elsewhere (Veal et al., 2000; Gruden et al., 2004).
Immunomagnetic carriers have been used for cell separation and enrichment in the last decade. Nanometersized particles were found to be superior compared to microbeads (MB), since reaggregation of the particles is limited, which improves detection and enumeration accuracy (Miltenyi et al., 1990). NIMP and antibody conjugated MB have been applied to separation of a wide range of bacteria (Bard and Ward, 1997; Seo et al., 1998; Šafař́k and Šafař́ková, 1999; Liu et al., 2001; Favrin et al., 2003), including Mycobacterium tuberculosis (Mazurek et al., 2001), M. paratuberculosis (Grant et al., 1998), and M. ulcerans (Roberts and Hirst, 1997) in clinical matrices. However, not until recently have magnetic carriers and FCM been coupled to separate and enumerate bacteria such as Escherichia coli, Salmonella enter$i c a$, and undefined sediment consortium samples (Furtado and Casper, 2000; Kusunoki et al., 2000) and to recover M. immunogenum in metalworking fluids (Chang et al., 2005).

Traditional immunofluorescence (IF) has been applied to detect mycobacteria in clinical matrices (Ortalo-Magné et al., 1996; Yi et al., 1998) and also in metalworking fluids (Chang et al., 2005). However, it has been shown that the recovery rate in IF was relatively low (Chang et al., 2005). In this study, we report a systematic comparison of labeling efficiency and specificity of NIMP and FAb (modified IF) on mycobacterial detection in a mixed community in a semisynthetic MWF by using flow cytometry and different data analysis approaches.

\section{EXPERIMENTAL PROTOCOLS}

\section{Culture condition and MWF preparation}

M. immunogenum (ATCC\#700506), M. parafortuitum (ATCC\#19686), Pseudomonas aeruginosa (ATCC \#33988), Pseudomonas pseudoalcaligenes (ATCC\#31200), Citrobacter freundii (ATCC\#51597), and Micrococcus luteus (ATCC\#10773) were obtained from the American Type Culture Collection (ATCC, Manassas, VA). M. immunogenum is the most probable causative agent in HP outbreaks in MWFs and M. parafortuitum can serve as a reference to check the antibody specificity to serve as a genus-wide probe. The other four bacteria were often isolated from in-use MWFs. M. immunogenum and $M$. parafortuitum were inoculated into Middlebrook $7 \mathrm{H} 9$ medium with oleic acid-albumin-dextrose-catalase (OADC) enrichment (Fisher Scientific, Pittsburgh, PA) and incubated for at least 59 and $38 \mathrm{~h}$ at $30^{\circ} \mathrm{C}$ to reach a stationary growth phase before testing, respectively. $C$. freundii, $P$. pseudoalcaligenes, $P$. aeruginosa, were incubated in Becton Dickinson 233000 nutrient broth (Fisher Scientific) for $12 \mathrm{~h}$ at $30^{\circ} \mathrm{C}$ to reach a stationary 
phase before testing. Micrococcus luteus was inoculated into Becton Dickinson 237400 brain heart infusion broth (Fisher Scientific) and incubated for $20 \mathrm{~h}$ at $30^{\circ} \mathrm{C}$ on a shaker to reach a stationary phase before testing. A semisynthetic MWF, including its recipe and components (Table 1), was kindly provided by MWF manufacturers. The MWF solution ( $\mathrm{pH} 8.8$ to 9.1) was pale yellow and translucent, indicating a fine oil-in-water emulsion. Before test, MWF solution was sterilized by autoclaving.

\section{Sample preparation}

All cell samples were fixed before any further pretreatment by mixing the cells with $10 \%(\mathrm{v} / \mathrm{v})$ ice-cold formalin (final concentration: $2 \%$ formalin) and incubated in a $-20^{\circ} \mathrm{C}$ freezer for half an hour. The impact of fixation on recovery and labeling efficiency has been reported previously (Chang et al., 2005). Since aggregation of mycobacterial cells interferes with accurate optical quantification using both EFM and FCM, the cells were dispersed by a 45-s exposure of probe sonication at amplitude level 2 (Virsonic 50, Virtis Company Inc., Gardiner, NY). Sonication after formalin fixation has been suggested to reduce the damage due to strengthened cellular layer (Tso and Taghon, 1997) and the specific results of mycobacterial cell disaggregation in MWFs were reported previously (Chang et al., 2004). The microcentrifuge tubes were put into an ice bath while applying probe sonication to prevent sample heating and cavitation (Harrison, 1991). Each cell sample was prepared by adding stationary-phase culture into the model MWF to achieve the initial target cell densities $\left(\sim 10^{7}\right.$ cells $\left./ \mathrm{mL}\right)$ and then incubated in MWF solution with 3\% final concentration of bovine serum albumin (BSA) for $2 \mathrm{~h}$ to block nonspecific bindings between the primary $\mathrm{Ab}\left(1^{\circ}\right.$ $\mathrm{Ab})$ and the surface antigens of nontarget bacteria.

\section{NIMP preparation}

Sixty nanometer (nm) diameter and 20-nm diameter magnetite particles were synthesized by the coprecipita-

Table 1. Recipe of a semisynthetic MWF.

\begin{tabular}{lr}
\hline Component & $\%, w / w$ \\
\hline Mineral oil & 0.750 \\
Tall oil fatty acid & 0.185 \\
Surfactant, sodium petroleum sulfonate (SPS) & 0.300 \\
Fatty amide & 0.400 \\
Borate corrosion inhibitor & 0.300 \\
Coupler & 0.075 \\
Monoethanolamine & 0.095 \\
EDTA & 0.008 \\
DI water & 97.887 \\
\hline
\end{tabular}

tion method (Cornell and Schwertmann, 2003) and purchased from Sigma-Aldrich Co. (Milwaukee, WI; Cat \#. 637106), respectively. There are two major different ways to conjugate the antibodies onto these magnetic carriers: one is random conjugation, and the other is oriented conjugation. The most common approaches for these two different conjugation methods are (1) zero-length linker 1-(3-dimethylaminopropyl)-3-ethyl carbodiimide (CDI) (Mehta et al., 1997; Konerachá et al., 2002; Huang et al., 2003) and (2) (3-aminopropyl) triethoxysilane (APTES) (Weetall, 1976, 1992; Shinkai et al., 1992; Zhang et al., 2002) coupled with protein A or G, respectively. Whereas $\mathrm{CDI}$ can link the carboxyl group of the $1^{\circ} \mathrm{Ab}$ onto the hydroxyl group on the surface of nano-magnetic particle (NMP) without fixed orientation, APTES is able to achieve oriented conjugation of $1^{\circ} \mathrm{Ab}$ by interlinking with protein A or G. Due to the high specificity of protein $\mathrm{A}$ and $\mathrm{G}$ toward the Fc fragment of immunoglobulin $\mathrm{G}(\mathrm{IgG})$, the antigen-specific sites are left free.

The protocol for oriented conjugation of $1^{\circ} \mathrm{Ab}$ onto nanoparticles was modified from other literature (Weetall, 1976, 1992; Shinkai et al., 1992; Zhang et al., 2002). Briefly, $50 \mathrm{mg}$ of nanoparticle was transferred into a 50$\mathrm{mL}$ solution of $10 \%(\mathrm{v} / \mathrm{v})$ 3-aminopropyltriethoxysilane (APTES, Sigma-Aldrich, \#A3648) in anhydrous toluene and mixed by vortex and sonication bath $(10 \mathrm{~min})$. The 60 -nm particles solution was incubated at $30^{\circ} \mathrm{C}$ in an incubator (Innova 4000 incubator shaker, New Brunswick Scientific Co., Inc., Edison, NJ) for $10 \mathrm{~h}$, and the 20-nm solution at $45^{\circ} \mathrm{C}$ in a bath sonicator (FS6, Fisher Scientific) for $10 \mathrm{~h}$. After this incubation, the nanoparticles were rinsed with dry toluene (once), a mixture of dry toluene and methanol (1:1 v/v, once), methanol (once), and milliQ water (twice) in a GS-6 Centrifuge (Beckmann Instrument, Inc. Palo Alto, CA) at 3,000 rpm for 5 min. Fifty milliliters of $2.5 \%$ (v/v, final concentration) glutaraldehyde (in 0.1 M PBS, $\mathrm{pH} 7.0$ ) were added to resuspend the nanoparticles, and the solution was incubated at $4^{\circ} \mathrm{C}$ for 1 $\mathrm{h}$ in the dark. After incubation, the solution was rinsed with milli-Q water (three times) at 3,000 rpm for $5 \mathrm{~min}$ on a GS-6 centrifuge. The pellet was resuspended in $20 \mathrm{~mL}$ of ice-cold 0.1 M PBS (pH 7.0) by pipetting and sonicating, if necessary. Then, freshly prepared $100 \mu \mathrm{L}$ of protein A (Sigma-Aldrich \#P368) reagent $(10 \mathrm{mg} / \mathrm{mL}$ in $0.1 \mathrm{M} \mathrm{PBS})$ were added into the $1.0-\mathrm{mL}$ aliquot of the above prep ( $\mathrm{Lu}$ et al., 1996; Caruso, 1999; Turková, 1999) and incubated at $4^{\circ} \mathrm{C}$ for $12 \mathrm{~h}$ in dark. After this incubation, the nanoparticles were rinsed with ice-cold PBS at 3,000 $\times g$ for 5 min in a microcentrifuge (Micro12 microcentrifuge, Fisher Scientific) for three times to remove unbound protein A. The pellet was resuspended to $0.5 \mathrm{~mL}$ in PBS and $50 \mu \mathrm{L}$ of $1^{\circ} \mathrm{Abs}$ were added. After incubation at $4^{\circ} \mathrm{C}$ for at least $1 \mathrm{~h}$, the nanoparticles were washed three times to remove 
unbound $1^{\circ}$ Abs with ice-cold PBS at 3,000 $\times g(5 \mathrm{~min})$, $6,000 \times g(5 \mathrm{~min})$, and $12,000 \times g(5 \mathrm{~min})$. At the end, the pellet was resuspended to $1.0 \mathrm{~mL}$ in ice-cold PBS for working concentration and kept at $4^{\circ} \mathrm{C}$ before use. After this preparation, the $1^{\circ} \mathrm{Ab}$ should be bound onto the nanoparticles with active binding sites facing the solution phase. After comparing the labeling efficiency of these magnetic carriers with different diameters, effectively labeled mycobacterium over total mycobacteria in pure culture test, $20-\mathrm{nm}$ nanoparticles were selected for further tests.

\section{Labeling with NIMP and primary Abs}

After 2-h incubation of the testing samples in MWF containing 3\% BSA, NIMPs and free Abs were added into separate sets of samples and incubated on an endto-end shaker at room temperature for $30 \mathrm{~min}$ in the dark. Three primary antibodies $\left(1^{\circ} \mathrm{Ab}\right)$ have been tested (polyclonal rabbit antimycobacterium IgG (\#6398-0006, Biogenesis, Inc., Kingston, NH; polyclonal rabbit anti-Mycobacterium tuberculosis IgG, \#4601, ViroStat, Inc., Portland, ME; polyclonal rabbit anti-Mycobacterium tuberculosis IgG, \#20MR-50, Fitzgerald Industries International, Inc., Concord, MA). The optimized titers, 10 $\mu \mathrm{L}$ of NIMPs working reagent and $10 \mu \mathrm{L}$ of free Abs reagent ( 1,000 time dilution of original concentration) per $240 \mu \mathrm{L}$ of cell sample, were defined through titer tests, which will be discussed in later sections.

\section{Secondary antibody and nucleic acid dye staining}

After incubation, all samples were added with $100 \mu \mathrm{L}$ of a secondary $\mathrm{Ab}\left(2^{\circ} \mathrm{Ab}\right)$, Alexa Fluor ${ }^{\circledR} 647, \mathrm{~F}\left(\mathrm{ab}^{\prime}\right)_{2}$ fragment of goat antirabbit $\operatorname{IgG}(\mathrm{H}+\mathrm{L}),(\mathrm{A}-21246$, Molecular Probes, Eugene, OR). After adding $2^{\circ} \mathrm{Ab}, 4 \mu \mathrm{L}$ of a nucleic acid dye, PicoGreen ${ }^{\circledR}$ (P-7581, Molecular Probes), and $350 \mu \mathrm{L}$ of a resolving agent, $N, N$-dimethylformamide (DMF), were added to each sample. Those samples were incubated for $15 \mathrm{~min}$ in a $37^{\circ} \mathrm{C}$ water bath before slide preparation and FCM quantification (Chang et al., 2005). This step is necessary when the optical interference from MWF components is significant. After incubation, all samples were rinsed twice with $0.3 \%$ BSA (in PBS) on a centrifuge for $5 \mathrm{~min}$ at $12,000 \times \mathrm{g}$. The final pellet was resuspended in ice-cold PBS to 500 $\mu \mathrm{L}$, and $400 \mu \mathrm{L}$ of DMF was added into each vial and mixed well. The final samples were split for enumeration on FCM and epifluorescent microscopy. To be noticed, this two-rinse FAb protocol is significantly different from the traditional six-rinse protocol of IF, where two rinses were to clean up the matrices, two rinses to get rid of unbound $1^{\circ} \mathrm{Ab}$, and two rinses for the removal of unbound $2^{\circ} \mathrm{Ab}$ (Porter, 1999).

\section{Analytical procedures}

Epifluorescent microscopy (EFM). The samples were vacuum-filtered through a black polycarbonate filter paper (25 mm diameter; $0.22 \mu \mathrm{m}$ ) (Osmonics, Inc., Pittsburgh, PA). The filter paper was then transferred to a microslide and covered with coverglass for EFM enumeration by following published protocol (Kepner and Pratt, 1994). A Zeiss Axioplan microscope (Zeiss, Germany) mounted with a 50-W Osram UV mercury lamp was employed to count the bacteria. Pictures were taken using Zeiss AxioCam MRc digital camera and AxioVision software version 4.0 (Carl Zeiss Vision GmbH, Hallbergmoos, Germany).

Flow cytometry $(F C M)$. A dual laser FACSCalibur ${ }^{\mathrm{TM}}$ flow cytometer (BD, Biosciences Inc., San Jose, CA), equipped with a $15-\mathrm{mW}$ air-cooled 488-nm argon-ion laser and a second red-iodide 635-nm laser, was used. Before each test, the instrument was calibrated by using a CaliBrite ${ }^{\mathrm{TM}}$ bead (Cat.\# 340486) reagent. Voltages for each of the photomultiplier tubes were adjusted to get good separation between the population of interest and the background. The side-scatter threshold was set at 52, and the acquisition algorithms were set to either "at least 20,000 events or $20 \mathrm{~s}$ " or "at least 200,000 events or 20 $\mathrm{s}$ " depending on sample conditions. For quantitative enumeration, TruCount ${ }^{\mathrm{TM}}$ (Cat. \#340567) tubes containing precounted dye-coated beads were used per manufacturer's instruction. These coated beads have high sidescattered light intensity, and can be easily separated from other populations on fluorescent light detector (FL) 2 detector (563-607-nm wavelength). For PicoGreen ${ }^{{ }_{-}}$ stained and Alexa Fluor ${ }^{\circledR} 647$ labeled cells, data on FL1 (515-545-nm wavelength) and FL4 (653-669-nm wavelength) were selected for further data analysis. CellQuest ${ }^{\mathrm{TM}}$ Software (BD Biosciences) was utilized to examine each data file and to ensure that the population of interest was separated from the background.

\section{FCM data analysis}

Visualization analysis. Visualization analysis of FCM data is an intuitive way to separate the population of interest from the background noise and works well in a clear matrix, such as PBS, and has been widely applied in medical research (Boddy et al., 2001; Nguyen et al., 2003). By comparing the dot plots of test samples with that of the blank sample (negative control), one can easily differentiate the population of interest from the background by specific light intensities. For example, for cells stained with nucleic acid dye, such as $\mathrm{SYTO}^{\circledR}$ or PicoGreen ${ }^{\circledR}$, a fluorescent light detector 1 (FL1, green fluorescence) light intensity vs. side-scattered light in- 
tensity dot plot was processed and visually examined to ensure the population of interest was separated from the background. Similarly, for the two-color approach, $M$. immunogenum, which was stained with green nucleic acid dye (high light intensity on FL1) and red Alexa Fluor ${ }^{\circledR} 647$ (high light intensity on FL4, red fluorescence), a gating strategy was utilized to select the effective labeled mycobacterial population. In this study, CellQuest ${ }^{\mathrm{TM}}$ Software was utilized to examine each data file. A region statistics or a gate statistics can be obtained by choosing an individual dot-plot in CellQuest ${ }^{\mathrm{TM}}$.

Cluster analysis. To filter out the true positive mycobacterial population in a noisy FCM dataset, hierarchical cluster analysis was selected to use in this study due to its simplicity, wide application, and insensitivity to data file structures (Romesburg, 1984). Hierarchical cluster analysis utilizes simple algorithm to calculate the Euclidean distance from one data point (or cluster) to the other data point (or cluster) by the following equation:

$$
d_{j k}=\left[\frac{\sum_{i=1}^{n} W_{i}\left(X_{i j}-X_{i k}\right)^{2}}{\sum_{i=1}^{n} W_{i}}\right]^{1 / 2}
$$

where $d_{j k}$ is the Euclidean distance from point (cluster) $j$ to point (cluster) $k$ in a space with dimensionality of $n . X_{i}$ represents the attribute value of the cluster or point measured at the $i$ th dimension. $W_{i}$ is the weight selected for $i$ th dimension for computation (Gibbons and Coleman, 2001).

Cluster analysis in all six dimensions (forward and side scatter, as well as four filters) was performed by using statistical software, MiniTab (Minitab, Inc., State College, PA), on a Microsoft Windows ${ }^{\circledR}$ based SUN W1100Z workstation equipped with Opteron processor (SUN Microsystems, Santa Clara, CA). File conversion from CellQuest ${ }^{\mathrm{TM}}$ FCS format to text file format was done by using FCS Assistant (version 1.1a, FCSpress, Inc., UK). Several macros in Microsoft Excel ${ }^{\circledR}$ were written to facilitate log-transformation and truncation of data files since there is a memory limitation for the workstation to handle the computation.

Cluster analysis aided visualization analysis. Due to the disadvantages of traditional visualization analysis and cluster analysis, lower specificity for the former and timeconsuming operation for the latter, a novel FCM data analysis approach was developed and designated as cluster analysis aided visualization analysis (CAAVA). This method requires the pure bacteria strain data files to be processed by hierarchical cluster analysis to obtain their unique cluster shapes in a multiple dimensional space.
Then, a gating strategy is established accordingly to rapidly process the data files by using CellQuest ${ }^{\mathrm{TM}}$. By applying this data analysis method, better accuracy and faster processing of FCM data can be achieved.

Kolmogorov-Smirnov test (K-S test). To assess whether one cluster is similar to another, a nonparametric statistical testing as described by Kolmogorov and Smirnov (Kolmogorov, 1933) was implemented. The KolmogorovSmirnov test (K-S test) has been applied to compare the similarity of histograms from flow cytometry-type data since the 1970s (Young, 1977). This test is superior to chisquare test, since the chi-square test may fail when testing large datasets (Yen, 1992) and chi-square test is based on the parametric assumption that the sampling error has normal (Gaussian) distribution (Young, 1977). In the K-S test, for two sample distributions with $m$ and $n$ events (or cases) and with cumulative probability functions of $F(x)$ and $S(x)$, respectively, a testing statistic $D$ can be defined as

$$
D=\operatorname{Max}|F(x)-S(x)|
$$

For either $m$ or $n$ is larger than 12 and for two-tail testing, a critical $D$ value can be calculated by using the following equation (Young, 1977; Yen, 1992; Lamprariello, 2000)

$$
D_{\text {crit }}=D_{\alpha / 2}=1.63 \times s(n) \text { for } \alpha=0.01
$$

where $s(n)=\sqrt{(m+n) /(m n)}$.

If the resultant $D$ is greater than this value, the hypothesis $\mathrm{H}_{0}$ : " $F(x)$ and $S(x)$ are similar" is rejected. To examine whether a resultant $D$ is greater than $D_{\text {crit }}$, a P-P plot of $F(x)$ and $S(x)$ and the $D_{\text {crit }} / s(n)$ were used (Deutsch and Journel, 1997). If two histograms exhibit a similar shape, the curve will follow closely a 45 degree slope trend line in this plot. The cumulative probability curves, $F(x)$ and $S(x)$, can then be drawn on this plot to assess whether any point is outside of the boundary. To generate the P-P plots, a program developed by Deutsch and Journel (1997) was used.

\section{RESULTS AND DISCUSSION}

\section{Pretreatment and amendment of M. immunogenum in $M W F$ s}

To achieve reliable cell enumeration, it is imperative for the cells to be suspended as individual cells (Nebevon-Caron et al., 2000). Probe sonication resulted in effective disaggregation of $M$. parafortuitum and M. immunogenum based on EFM and FCM quantification, giving a good linear correlation between both enumeration methods (Chang et al., 2004). It is plausible that the components in the semisynthetic MWF had prevented the 
mycobacterial cells from reaggregating (Calleja, 1984; Ortalo-Magné et al., 1996). Optical interference due to MWF matrices has been successfully overcome by adding low-polarity solvents (Chang et al., 2004, 2005). Recently, other researchers (Skerlos et al., 2003; Veillette et al., 2004) have also reported their enumeration results of mycobacteria. The initial cell concentrations were always lower than $10^{8}$ cells $/ \mathrm{mL}$, which is significantly lower than the observed initial cell concentration of both M. immunogenum and M. parafortuitum in 7H9 medium in this study, $<10^{9}$ cells $/ \mathrm{mL}$. The lower cell densities may be due to incomplete disaggregation of mycobacterial cells. This disaggregating measure is also very relevant to the real-world samples, since biofilm or microbial aggregates are often mixed microbial communities instead of pure cultures (Atlas and Bartha, 1998). Therefore, full disaggregation of microbial aggregates in MWFs can also avoid incorrect enumeration of mycobacterial cell density in more complex microbial community samples. To reduce the optical interference caused by MWF emulsion matrix, DMF was added and several different incubation time periods were tested. A 15-min incubation period was selected due to better FCM results, judged by how well the population of interest was separated from the background. Pure culture samples of six different strains were tested and two mycobacterial strains showed distinct higher FL1 light intensity than others.

Figure 1 shows the dot plots of $M$. immunogenum, $P$. aeruginosa, and blank samples by using FAb and NIMP protocols and two different gating strategies. For NIMP protocol, in Fig. 1A and B, in M. immunogenum samples, a population with much higher FL1 was present by comparing the dot plots of different samples. The second row of dot plots were generated by ordering the R1-region gated population to be shown on a different FL4 vs. side scatter light (SSC) plot. The population left out in Fig. 1b showed lower FL4 light intensity. For FAb protocol, in Fig. 1C and D, similar higher FL4 mycobacterial population was present and, similarly, the population left out in the second gating strategies did not impact the FL4 vs. SSC intensity results significantly. By comparing the

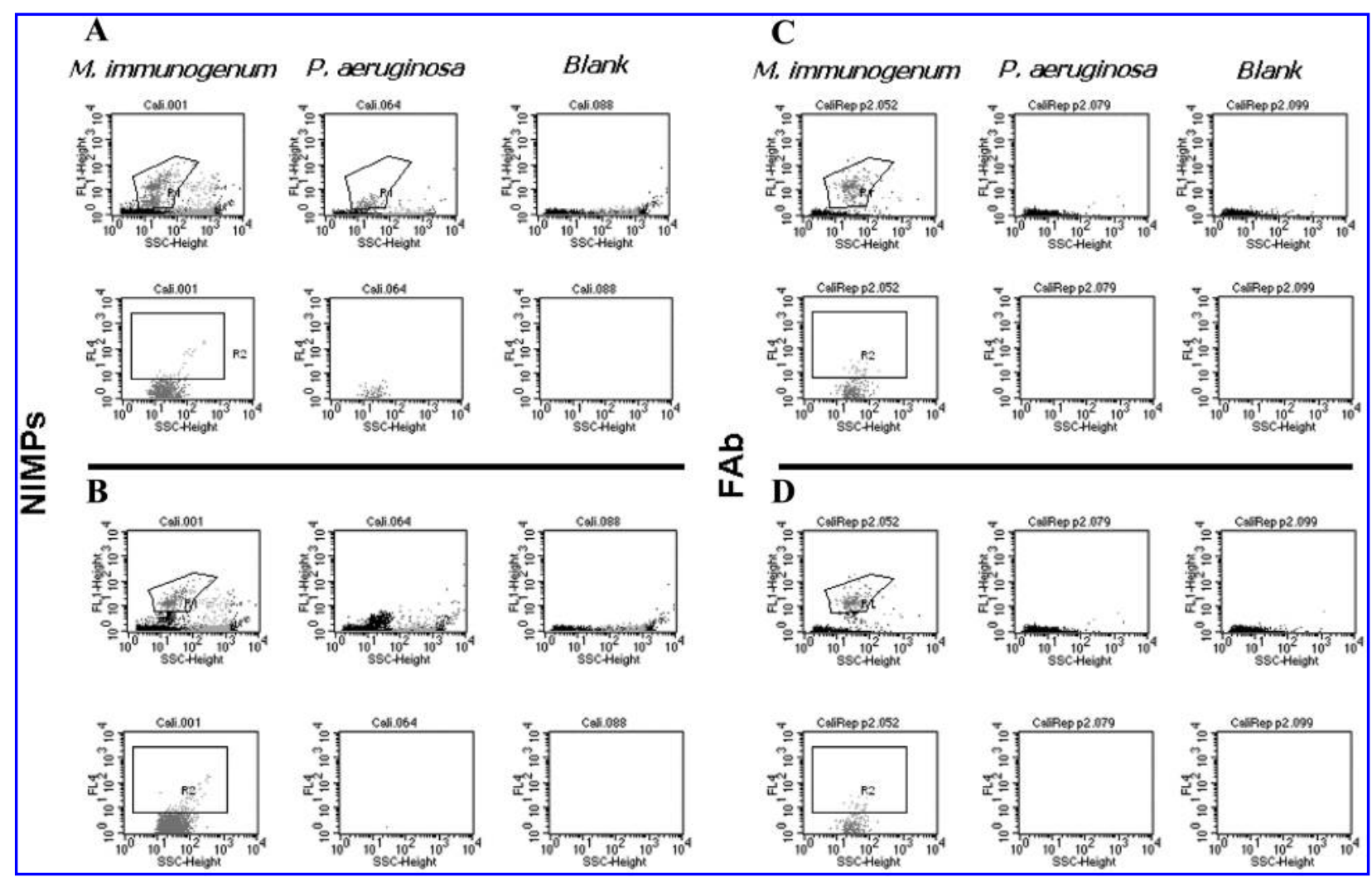

Figure 1. Dot plots of M. immunogenum, P. aeruginosa, and blank sample in MWF. Dot plots are generated by using two different gating strategies: all populations with FL1 higher than unseeded samples using NIMP protocol (A); population with FL1 higher than all other nonmycobacterial samples using NIMP protocol (B); all population with FL1 higher than unseeded samples using FAb protocol (C); and population with FL1 higher than all other nonmycobacterial samples using FAb protocol (D). $P$. aeruginosa was chosed due to it showed the highest FL1 among all nonmycobacterial samples. 
plots of NIMP and FAb, the latter exhibit much less noise and the second gating strategies resulted in less noise for NIMP results. Therefore, for visualization analysis, the second gating strategy was chosen to process all the data files.

The significantly higher FL1 light intensity could have resulted from either better penetration of PicoGreen ${ }^{\circledR}$ into mycobacterial cells or less DNA denaturation due to DMF in mycobacterial cells. The incomplete denaturation of DNA in DMF has been previously investigated (Cortada and Subarina, 1977). Their results indicated that the stability against DMF denaturation increases with the guanine plus cytosine content $(\mathrm{G}+\mathrm{C} \%)$ and the base sequence plays a minor role. Since Mycobacterium spp., Micrococcus spp., $P$. aeruginosa, and $C$. freundii have $\% \mathrm{G}+\mathrm{C}$ contents of 62-70, 66-73, 65.7, and 50.1\%, respectively (HaywardFarmer and Otto, 2003; Madigan et al., 2003), DNA denaturation due to $\mathrm{G}+\mathrm{C} \%$ by DMF cannot explain the observed FL1 difference among different species. Instead, the thick hydrophobic outer capsule layer of mycobacterial cells may have effectively blocked DMF but let the hydrophobic PicoGreen ${ }^{\circledR}$ stain diffuse into the cell. Thus, mycobacterial cells would be more likely to exhibit FL1 light intensity, relative to the other bacterial strains. $P$. aerugi$n o s a$, which was the only strain among the nonmycobacterial bacterial strains known to form biofilms and cellular aggregates, showed the highest intensity FL1 signals, further corroborating the hypothesis that the outer layer of the microbial cells may significantly impact PicoGreen ${ }^{\circledR}$ staining in a DMF-amended solution.

Longer incubation times of $2^{\circ} \mathrm{Ab}$ were tested and shown to exhibit lower FL4 light intensity. This is consistent with the previously reported results suggesting that, within a 15-60-min incubation period with 5-40\% $\mathrm{DMF}, \mathrm{Ab}$ may undergo irreversible conformational changes (Melnikova et al., 2000). Miroliaei and NamatGorgani (2002) suggested that DMF may cause substrate inhibition and changes in protein conformation. Since an incubating period of less than 15 min does not allow PicoGreen ${ }^{\circledR}$ to stain mycobacteria well, 15-min incubation is considered optimal for the incubation with a cocktail of PicoGreen ${ }^{\circledR}, 2^{\circ} \mathrm{Ab}$, and DMF.

\section{Labeling efficiency of $M$. Immunogenum}

To determine effectively labeled mycobacteria on FCM, labeling efficiency $(L E)$ was defined as follows:

$$
L E=\frac{N_{\mathrm{FL} 4}}{N_{\mathrm{FL} 1}}
$$

where $N_{\mathrm{FL} 4}$ is the number of cells showing higher FL4 light intensity than the background (as captured by gate R2 in Fig. 1), and $N_{\text {FL1 }}$ is the number of cells showing higher FL1 light intensity than the background (as captured by gate R1 in Fig. 1).

$L E$ is the ratio of effectively labeled mycobacteria to all mycobacteria with double-stranded DNA if tested in a pure culture, or the ratio of effectively labeled mycobacteria to all bacteria with double-stranded DNA if tested in a mixed bacterial community. Three different $1^{\circ}$ Abs were conjugated onto $20-\mathrm{nm}$ nanoparticles and went through the testing protocol for pure M. immunogenum. The results of labeling efficiency and cost of these three $1^{\circ}$ Abs indicated that the ViroStat IgG and Fitzgerald IgG exhibit a significantly higher $L E$ than the Biogenesis product.

Instrumental detection limit on the sizes of fluorescent dye stained viruses for FACSCalibur ${ }^{\mathrm{TM}}$ have been reported in the 30-50 nm range (Brussaard et al., 2000). The labeling of cells with both FAb and NIMP is expected to result in a wide range of particle dimensions and associated fluorescent characteristics. The detection of $M$. immunogenum and $C$. freundii using NIMP and/or $\mathrm{FAb}$ is as shown in Fig. 2. From left to right, three plots are shown to capture the events on (left) the FL1 vs. SSC plot, which captures all particles stained with PicoGreen ${ }^{\circledR}$ (only those events in $\mathrm{R} 1$ represent intact bacteria); (middle) the FL4 vs. SSC plot captures all events not selected in the R1 region; and (right) further examination of those events (in region R4 or R5) on a FL4 vs. FSC (size) plot. In the case of NIMP-labeled $M$. immunogenum, the oval shape of events in the middle plot indicated that those events include particles ranging from small $(<1 \mu \mathrm{m})$ to very large $(>10 \mu \mathrm{m})$. In other words, the NIMP protocol results in the formation of at least two populations: the NIMP-bacteria cluster (R1), and a population with a wide range of size and high FL4 light intensity. Since they do not form a tight cluster within the FL1 filter, it can be inferred that they do not possess similar amounts of double-stranded DNA and do not have similar internal complexity as intact cells. Thus, this second cluster may represent NIMP aggregates not bound to cells which formed during centrifugation or nonuniform cell debris with various sizes and the complex of multiple $1^{\circ} \mathrm{Ab}$ and $2^{\circ} \mathrm{Ab}$. By comparing these results with the results generated from negative control samples (no cells), it is confirmed that the oval-shaped population on the FL4 vs. FSC dot plot is mainly the NIMPs with $2^{\circ} \mathrm{Ab}$.

Figure 2D-F showed the results through the same operation on a data file generated by using FAb protocol on a mycobacterial sample. From these three plots, the noise was observed to be much less on a FL1 vs. SSC dot plot than the one generated by using NIMP protocol. The sizes of selected population in region R5 appeared much smaller and their FL4 light intensity signals were much lower. Those are more like to be complexes of my- 


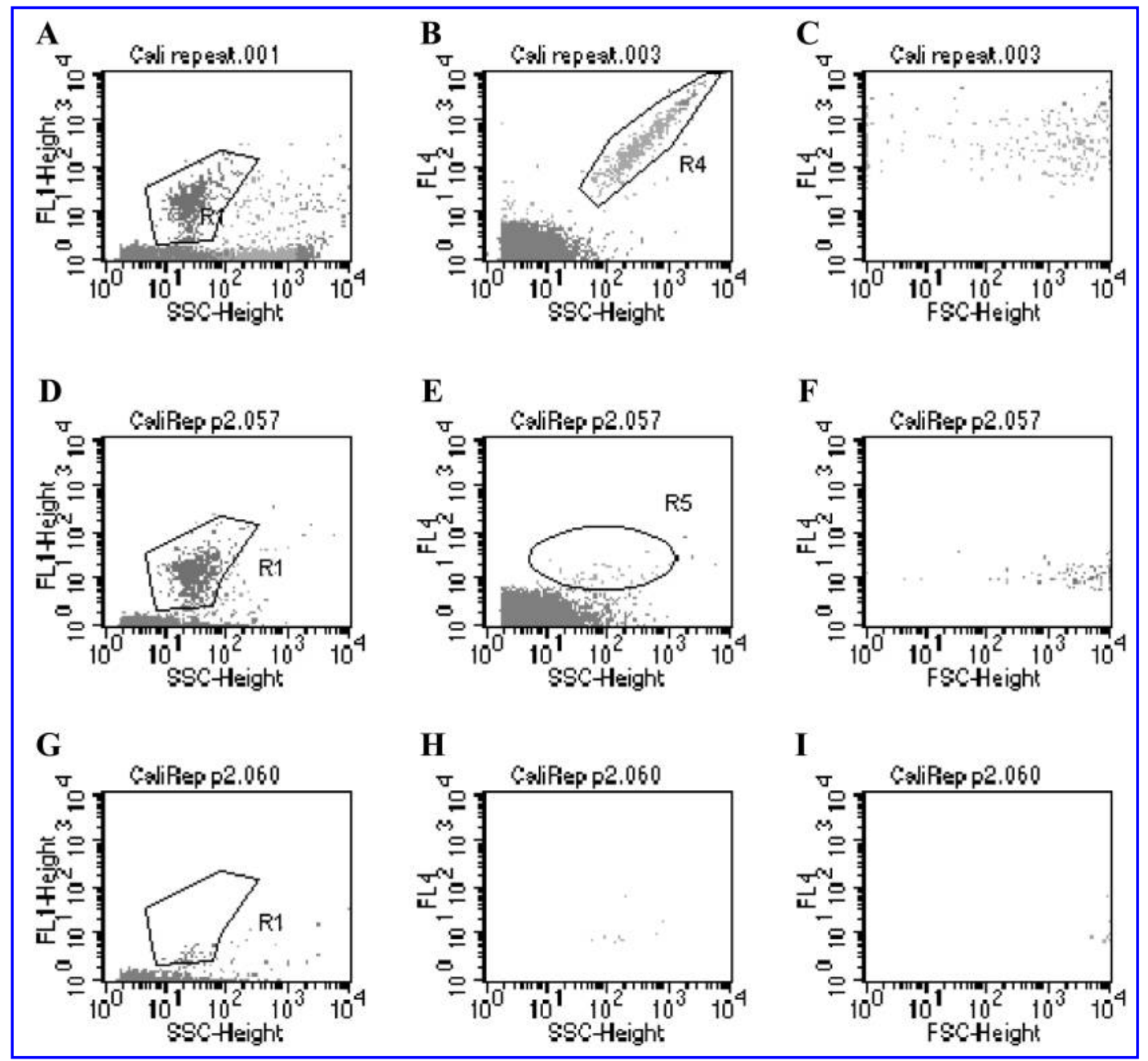

Figure 2. FCM analysis of M. immunogenum in MWF with NIMP (A-C); M. immunogenum in MWF with FAb (D-F); and C. freundii in MWF with FAb (G-I). (Legend: first plot-FL1 vs. SSC; second plot-FL4 vs. SSC; third plot—FL4 vs. FSC.)

cobacterial cell debris with $1^{\circ}$ and $2^{\circ} \mathrm{Ab}$. Because, in Fig. $2 \mathrm{~A}-\mathrm{C}$, there were very few free $1^{\circ} \mathrm{Ab}$ and, therefore, even cell debris was present, they would not have high FL4 to be separated out of the background. The debris would show high FL4 if they were labeled by NIMPs and $2^{\circ} \mathrm{Ab}$ and moderately high SSC light intensity, that is, higher granularity due to bound with NIMPs. Negative controls showed no presence of this specific population, further confirming that it was related to mycobacterial cells. Figure 2G-I showed the results of a $C$. freundii sample generated by using FAb protocol. In this case, the population outside of the gate R1 exhibited a low number of events with moderate light intensity. These are more likely to be complexes of $1^{\circ}$ and $2^{\circ} \mathrm{Ab}$. Figure 2I showed that the particle sizes were very small, and negative controls (no cells) also confirmed that these events are likely to be complexes of $1^{\circ}$ and $2^{\circ} \mathrm{Ab}$.
To define the optimal titer of NIMPs and FAb, a series of tests were conducted with five different concentrations of the FAb and NIMPs on three different strains: M. immunogenum, $C$. freundii, and $P$. aeruginosa. For $\mathrm{FAb}, 10 \mu \mathrm{L}$ of a 1000 fold dilution of original IgG concentration $(\sim 27 \mathrm{nM}$, estimated final concentration) was chosen based on superior specificity (low false positive results) and relatively high FL4 light intensity by comparing with the results of higher concentration. A further test on five different strains was performed on this specific titer and the results showed $100 \%$ specificity based on a test on three different strains. Similarly, an optimized titer of NIMPs, $10 \mu \mathrm{L}$ per $240 \mu \mathrm{L}$ sample, $\sim 1.4 \times$ $10^{12}$ particles $/ \mathrm{mL}$ (estimated by assuming $85 \%$ recovery for each rinse during NIMP preparation) was chosen.

False positive results from samples prepared using the NIMP protocol raised a question about the origin of the 
background noise on a FL1 vs. SSC dot plot. Due to the high fluorescent light from NIMP- $2^{\circ}$ Ab complexes (excited by the 488 -nm laser), their emission signal can be recorded even though Alexa Fluor ${ }^{\circledR} 647$ should have low excitation at shorter wavelengths (Molecular Probes Handbook). No clear separation can be determined among NIMP-microbial conjugates, NIMP- $2^{\circ} \mathrm{Ab}$ complexes and self-aggregated NIMPs on either a FL4 vs. SSC dot plot or a FL1 vs. SSC dot plot. This complicated the effective resolution of mycobacteria from other fluorescent particles in a mixed community samples and ne- cessitated a better data analysis method other than visualization analysis.

\section{Labeling efficiencies for mycobacteria in pure culture and mixed community samples}

Three different data analysis approaches were implemented in this study: traditional visualization analysis (VA), cluster analysis (CA), and cluster analysis aided visualization analysis (CAAVA). Visualization analysis has been applied to FCM data analysis since the 1970s

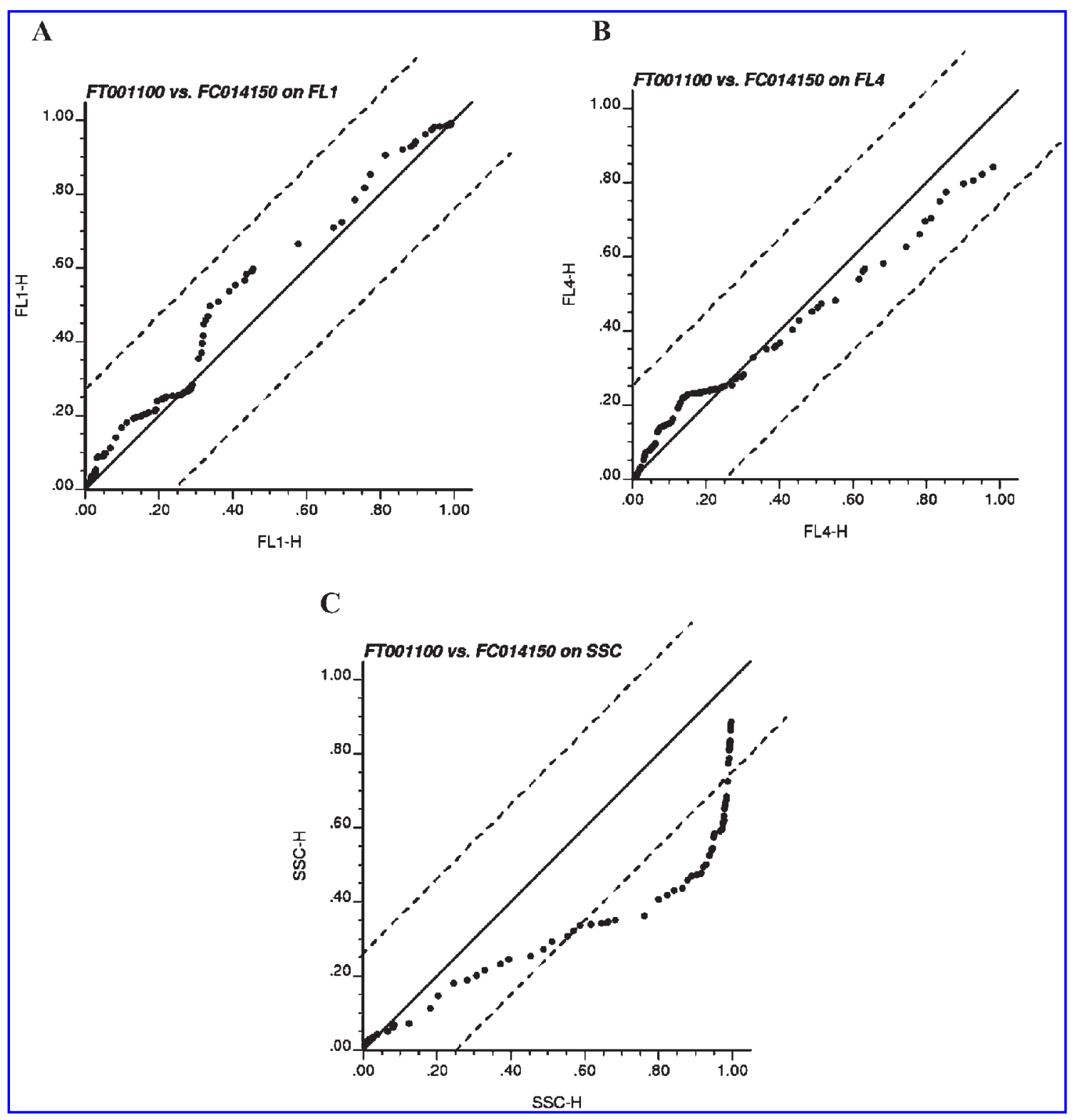

Figure 3. Example of P-P plots for a cluster from a mixed community sample and a cluster from pure strain $M$. immunogenum sample. From left to right, mixed community cluster (y-axis) vs. pure strain cluster (x-axis) on FL1 (A), FL4 (B), and SSC (C). 
(Salzman et al., 1978; Habbersett et al., 1979; Stöhr and Futterman, 1979) but has suffered low specificity when applied to environmental samples (McClelland and Pinder, 1994). Cluster analysis of FCM data has been applied widely to the identification of phytoplankton and mammalian cells (Murphy 1985; Schut et al., 1993; Barlage et al., 1999; Bohanec et al., 2002; Xu et al., 2002) but has not been applied to FCM data on bacterial tests coupled with the K-S test.

In this study, cluster analysis was first used to capture all seemingly related events in the multidimensional detector space as detailed in the Methods section. Hence, the clusters of events were generated for mycobacteria in pure culture and in mixed culture systems, which can be compared using cumulative frequency distribution curves (CFDs) of events, or represented in P-P plots. P-P plots were employed to graphically examine the similarity of two CFDs and to judge if they passed the K-S test. A curve close to the 45 degree line was generated from the two CFDs and two straight broken 45-degree lines represent the $D_{\text {crit }}$ (Fig. 3). One CFD from the putative mycobacterial cluster in mixed community samples was plotted along the $\mathrm{Y}$-axis and the other CFD from a pure culture mycobacteria cluster was plotted along $\mathrm{X}$-axis. The left-most P-P plot shows the test results on FL1. It is evident that this selected cluster passed the K-S test (at $\alpha=0.01$ ) on FL1, as well as on FL4. However, it did not pass the K-S test on the SSC dimension. These results indicated that these two populations exhibited significant similarity after being stained with PicoGreen ${ }^{\circledR}$ and $2^{\circ} \mathrm{Ab}$ but did not exhibit significant similarity in cellular granularity or internal complexity.

All data files from the FAb and NIMP protocols were used to generate P-P plots and K-S test was applied and the results summarized as shown in Table 2. For mixed community samples, only one file passed on all three dimensions $(2.8 \%)$ at both $\alpha=0.01$ and 0.001 , while all files $(100 \%)$ analyzed using CAAVA passed at $\alpha=$ 0.001 and $97.2 \%$ at $\alpha=0.01$. At an $\alpha=0.001$, the confidence level to reject the null hypothesis is $99.9 \%$ if the file did not pass the test. It has been reported that the
$\mathrm{K}-\mathrm{S}$ test may be too sensitive, and can reject the null hypothesis due to a possible shift of the CFDs from nonspecific binding or from instrument drift (Cox et al., 1988; Parikh et al., 1999; Lampareillo, 2000). Therefore, Cox et al. (1988) proposed an alternative method to test FCM data by assuming that a Poisson distribution existed within channels and a chi-square test can be applied. Parikh et al. (1999) suggested that this approach tends to decrease "sensitivity" but causes an increased likelihood of Type II errors. Considering that the histograms of mixed community samples in this study did not show an apparent shift, the K-S approach was defensible. Moreover, all the previous studies cited above tested only one dimension rather than the more favorable multiple dimensional examination. Cluster analysis has sound theoretical foundation but requires more advanced computing hardware and software. Visualization analysis is much faster, easier, and more flexible, but it is less accurate and may result in substantial incorrect interpretation.

A hybrid of both techniques, CAAVA, was created and tested to see if more accurate results can be obtained in a faster and easier fashion. Once clustered data are available from pure culture FCM data files, gating strategies can be implemented to resolve target organisms from interferences in mixed culture systems. The premise of this integrated approach is that cluster analysis based on simple systems can inform visualization analysis in complex systems.

From pure strain samples, $M$. immunogenum clusters can be easily sorted out by comparing FL1 light intensity with other clusters since they are the only biological events in the samples, and cluster analysis can take care of the overlapping events from other interferences in the FL1 dimension. This can be further confirmed by comparing the clusters with the clusters of negative control files. The shape of a typical $M$. immunogenum cluster on different dot plots is as shown in Fig. 4B. Hence, CAAVA capitalizes on determining the shape of the various relevant clusters (e.g., free NIMPs, free Abs, MWF matrix interference, etc.) using cluster analysis on pure culture

Table 2. K-S test on FL1, FL4, and SSC for mixed community samples by CAAVA by using P-P plots.

\begin{tabular}{|c|c|c|c|c|c|c|}
\hline Data analysis method & $\begin{array}{l}\text { Total } \\
\text { number of } \\
\text { files }\end{array}$ & $\alpha$ Value & $\begin{array}{c}\text { Number of } \\
\text { files passed } \\
\text { K-S test on } \\
\text { FL1 }\end{array}$ & $\begin{array}{c}\text { Number of } \\
\text { files passed } \\
\text { K-S test on } \\
\text { FL4 }\end{array}$ & $\begin{array}{l}\text { Number of } \\
\text { files passed } \\
\text { K-S test on } \\
\text { SSC }\end{array}$ & $\begin{array}{c}\text { Number of } \\
\text { files passed } \\
K \text {-S tests } \\
\text { on all three }\end{array}$ \\
\hline \multirow[t]{2}{*}{ Cluster analysis } & 36 & 0.01 & $5(13.9 \%)$ & $5(13.9 \%)$ & $7(19.4 \%)$ & $1(2.8 \%)$ \\
\hline & 36 & 0.001 & $8(22.2 \%)$ & $11(30.5 \%)$ & $10(27.7 \%)$ & $1(2.8 \%)$ \\
\hline \multirow[t]{2}{*}{ CAAVA } & 36 & 0.01 & $36(100 \%)$ & $35(97.2 \%)$ & $36(100 \%)$ & $35(97.2 \%)$ \\
\hline & 36 & 0.001 & $36(100 \%)$ & $36(100 \%)$ & $36(100 \%)$ & $36(100 \%)$ \\
\hline
\end{tabular}




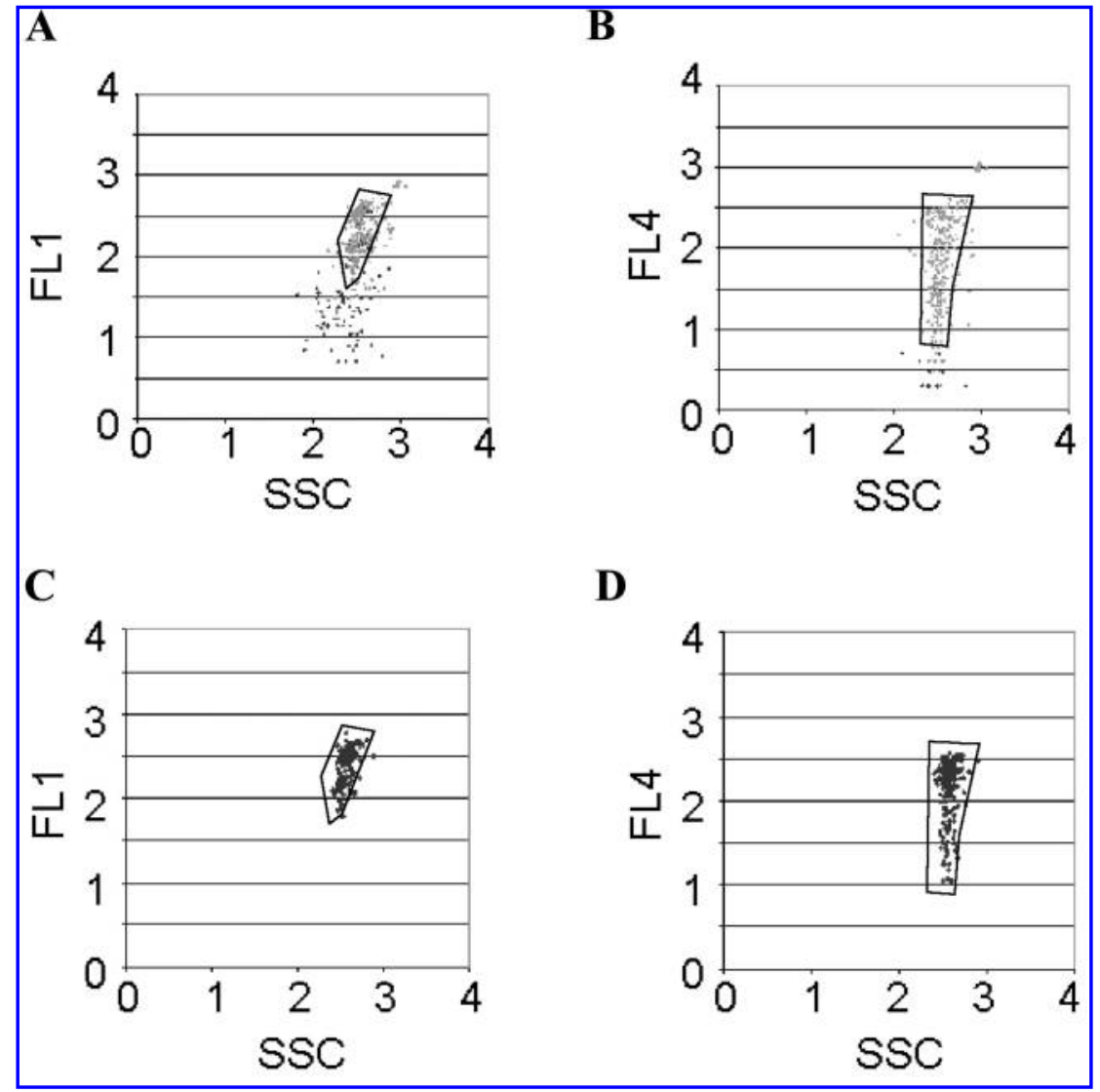

Figure 4. Clusters in mixed (top-delineated subset of events) and pure (bottom) cultures indicating the shape of mycobacterium clusters.

files. The polygonal shapes of the relevant events are then redrawn using the gating tools in CellQuest ${ }^{\mathrm{TM}}$ to capture these events in mixed microbial community samples. In the following section, this gating strategy (derived from cluster analysis of pure cultures on $M$. immunogenum) is employed to reprocess the mixed community data files, the data files of other pure bacterial strains, and negative controls to define labeling specificity.

Table 3. Labeling efficiency and specificity by using VA and CAAVA.

\begin{tabular}{|c|c|c|c|c|c|}
\hline \multirow[b]{2}{*}{ Technique } & \multirow[b]{2}{*}{ Test } & \multicolumn{2}{|c|}{ Labeling efficiency } & \multicolumn{2}{|c|}{ Specificity } \\
\hline & & $N I M P$ & $F A b$ & NIMP & $F A b$ \\
\hline \multirow[t]{7}{*}{ VA } & 1 & $13.9 \pm 7.2 \%$ & - & $85.2 \%$ & - \\
\hline & 2 & $3.6 \pm 0.7 \%$ & $9.9 \pm 1.2 \%$ & $92.6 \%$ & $100.0 \%$ \\
\hline & & $5.9 \pm 0.65(\mathrm{Mi})$ & $20.1 \pm 1.4 \%(\mathrm{Mi})$ & & \\
\hline & 3 & $22.1 \pm 5.0 \%(\mathrm{Mp})$ & $49.6 \pm 4.3 \%(\mathrm{Mp})$ & $77.8 \%$ & $80.0 \%$ \\
\hline & 4 & $5.2 \pm 0.4 \%(\mathrm{Mi})$ & $18.4 \pm 1.0 \%(\mathrm{Mi})$ & $84.4 \%$ & $84.4 \%$ \\
\hline & & $31.6 \pm 7.4 \%(\mathrm{Mp})$ & $66.7 \pm 18.0 \%(\mathrm{Mp})$ & & \\
\hline & Ave & $7.2 \pm 4.6 \%(\mathrm{Mi})$ & $16.1 \pm 5.5(\mathrm{Mi})$ & $85.0 \pm 6.1 \%$ & $88.1 \pm 10.5 \%$ \\
\hline \multirow[t]{5}{*}{ CAAVA } & 1 & $12.6 \pm 2.9 \%$ & - & $100.0 \%$ & - \\
\hline & 2 & $14.4 \pm 4.4 \%$ & $16.6 \pm 1.6 \%$ & $100.0 \%$ & $100.0 \%$ \\
\hline & 3 & $10.5 \pm 1.0 \%(\mathrm{Mi})$ & $24.4 \pm 1.2 \%(\mathrm{Mi})$ & $93.3 \%$ & $100.0 \%$ \\
\hline & 4 & $12.0 \pm 1.7 \%(\mathrm{Mi})$ & $20.4 \pm 1.7 \%(\mathrm{Mi})$ & $97.8 \%$ & $95.6 \%$ \\
\hline & Ave & $12.4 \pm 1.6 \%$ & $20.5 \pm 3.9 \%$ & $97.8 \pm 3.2 \%$ & $98.5 \pm 2.5 \%$ \\
\hline
\end{tabular}


The comparison of labeling efficiency and specificity of NIMP and FAb protocols of $M$. immunogenum in MWF by two different data analysis methods (VA and CAAVA) is tabulated in Table 3. By using VA alone (traditional FCM analysis), the labeling efficiency of FAb was significantly better than that of NIMP but did not show significant improvement on specificity. Interestingly, by applying CAAVA, the results suggested that NIMP performed almost as well as FAb in terms of both specificity and labeling efficiency. The reason for this improvement probably is due to more accurate capture of the true $M$. immunogenum cluster and application of more stringent gating criteria.

The K-S tests for all 36 mixed community files indicate that all files passed the statistical test with $\alpha=0.001$ and $97.2 \%$ passed the statistical test with $\alpha=0.01$ (Table 2). These results suggest that the populations from both pure strain samples and from mixed community selected by CAAVA exhibited much higher similarity in their cumulative frequency distributions.

\section{Calibration curves and detection limit for}

M. immunogenum in pure and mixed cultures

Since M. immunogenum showed very distinct FL1 light intensity after going through the FAb protocol, it can be gated on an FCM dot-plot in the presence of other bacteria using CAAVA, as shown earlier. A calibration curve for $M$. immunogenum in a ternary mixture with $C$. freundii and $P$. aeruginosa was established. The mixing ratios for $M$. immunogenum, $C$. freundii, and $P$. aeruginosa are $10^{7}: 10^{7}: 10^{7}, \quad 10^{6}: 10^{7}: 10^{7}, \quad 10^{5}: 10^{7}: 10^{7}$, $10^{4}: 10^{7}: 10^{7}$, and $10^{3}: 10^{7}: 10^{7}$ cells $/ \mathrm{mL}$. A calibration curve was determined as $Y=0.2785 \times X$ with $R^{2}=$ 0.9985 , where $Y$ was the FCM enumerated values and $X$ is the prepared cell densities. This calibration curve is good over five orders of magnitude based on VA. At the lowest cell concentrations $\left(10^{3}\right.$ cells $\left./ \mathrm{mL}\right)$, the FCM counts showed slight deviation from the curve. It is probably due to background noise that came from incomplete destabilization of surfactant-dye complex by the resolving agent (Chang et al., 2004). The same data files were reanalyzed by using CAAVA and the calibration curve is $Y=0.0061 \times X$ with $R^{2}=0.9998$, and it is good over four orders of magnitude. The detection limit by using FAb and VA was determined to be 250 cells $/ \mathrm{mL}$ but cannot be validated by CAAVA due to more stringent gating criteria. To date, no calibration curve and detection limit has been established by using NIMP protocol yet.

\section{CONCLUSION}

In this study, we compared the labeling efficiencies and specificities of NIMP and FAb protocols at optimized titers by applying traditional visualization analysis, cluster analysis, and cluster analysis aided visualization analysis (CAAVA). NIMP and FAb protocol performed equally well without significant difference in terms of labeling efficiency and specificity by using CAAVA as a validating tool. A calibration curve has been established across at least five orders of magnitudes with $R^{2}=$ 0.9985 by visualization analysis and four orders of magnitude by CAAVA with $R^{2}=0.9998$. Flow cytometric data files processed by using CAAVA show much higher statistical similarity between the deemed mycobacterial cluster in mixed community sample and the cluster from pure mycobacterial samples. The results strongly suggested that this technology, either FAb or NIMP with CAAVA on FCM, can be applied to practical routine measurements of mycobacteria in semisynthetic metalworking fluids due to its simplicity, high specificity, and short turn-around time.

\section{ACKNOWLEDGMENTS}

The authors would like to thank Dr. Kim F. Hayes (Dept. of Civil and Environmental Engineering, University of Michigan), Dr. Steven J. Skerlos (Dept. of Mechanical Engineering, University of Michigan), Dr. Alfred Franzblau (Dept. of Environmental Health Sciences, School of Public Health, University of Michigan), and Dr. Cyndee L. Gruden (Dept. of Civil Engineering, University of Toledo) for their constructive comments on this study. This research was partly funded by a scholarship to Dr. Shu-Chi Chang (No. 1999049) from the Ministry of Education, Taiwan, Republic of China.

\section{REFERENCES}

ATLAS, R.M., and BARTHA, R. (1998). Microbial Ecology: Fundamentals and Applications, 4th ed. Menlo Park: Benjamin/Cunnings Science Publishing.

BARD, D.G., and WARD, B.B. (1997). A species-specific bacterial productivity method using immunomagnetic separation and rediotracer experiment. J. Microbiol. Methods 28, 207.

BARLAGE, S., ROTHE, G., KNUCHEL, R., and SCHMITZ, G. (1999). Flow cytometric immunophenotyping of mature lymphatic neoplasias using knowledge guided cluster analysis. Anal. Cell. Pathol. 19, 81.

BD-BIOSCIENCES. (2001). Flow Cytometry Operator Training Manual. San Jose, CA: Becton Dickinson and Company.

BENNETT, E.O. (1972). The biology of metalworking fluids. Lubricat. Eng. 28, 237.

BERNSTEIN, D.I., LUMMUS, Z.I., SANTILLI, G., SISKOSKY, J., and BERSTEIN, I.L. (1995). A hypersensi- 
tivity pneumonitis disorder associated with exposure to metalworking fluid aerosols. Chest 108, 636.

BODDY, L., WILKINS, M.F., and MORRIS, C.W. (2001). Pattern recognition in flow cytometry. Cytometry 44, 195.

BOHANEC, B., LUTHAR, Z., and RUDOLF, K. (2002). A protocol for quantitative analysis of green fluorescent protein-transformed plants, using multiparameter flow cytometry with cluster analysis. Acta Biol. Cracoviensia Series Botanica 44, 145.

BRUSSAARD, C.P.D., MARIE, D., and BRATBAK, G. (2000). Flow cytometric detection of viruses. J. Virol. Methods 85, 175.

CALlEJA, G.B. (1984). Microbial Aggregation. Boca Raton, FL: CRC Press.

CARUSO, F. (1999). Fabrication of immunoglobulin monoand multi-layers and their application for immunosensing. In Lvov YM, Möhwald H (editors), Protein Architecture: Interfacing Molecular Assemblies and Immobilization Biotechnology. New York: Marcel Dekker, Inc., p. 201.

CHANG, S.-C., RIHANA, A., BAHRMAN, S., GRUDEN, C.L., KHIJNIAK, A.I., SKERLOS, S.J., and ADRIAENS, P. (2004). Flow cytometric detection and quantification of mycobacteria in metalworking fluids. Int. Biodeteriorat. Biodegrad. 54, 105.

CHANG, S.-C., ANDERSON, A.I., BAHRMAN, S.E., GRUDEN, C.L., KHIJNIAK, A.I., and ADRIAENS, P. (2005). Comparing recovering efficiency of immunomagnetic separation and centrifugation of mycobacteria in metalworking

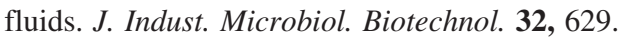

CHILDERS, J.C. (1994). The chemistry of metalworking fluids. In Byers JM, Ed. Metalworking Fluids, 1st ed. New York: Marcel Dekker, Inc., p. 165.

CORNELL, R.M., and SCHWERTMANN, U. (2003). The Iron Oxides. Weinheim, Germany: WILEY-VCH Verlag GmbH \& Co.

CORTADA, J., and SUBARINA, J.A. (1977). The imcomplete denaturation of DNA in N,N-dimethyl formamide. Biochim. Biophys. Acta 476, 203.

COX, C., REEDER, J.E., ROBISON, R.D., SUPPES, S.B., and WHEELESS, L.L. (1988). Comparison of frequency distributions in flow cytometry. Cytometry 9, 291.

DEUTSCH, C.V., and JOURNEL, A.G. (1997). GSLIB: Geostatistical Software Library and User's Guide. New York: Oxford University Press.

FAVRIN, S.J., JASSIM, S.A., and GRIFFITHS, M.W. (2003). Application of a novel immunomagnetic separation-bacteriophage assay for the detection of Salmonella enteritidis and Exchrichia coli $\mathrm{O} 157: \mathrm{H} 7$ in food. Int. J. Food Microbiol. 85, 63.

FURTADO, A.L.D., and CASPER, P. (2000). Different methods for extracting bacteria from freshwater sediment and a simple method to measure bacterial production in sediment samples. J. Microbiol. Methods 41, 249.

GIBBONS, R.D., and COLEMAN, D.E. (2001). Statistical Methods for Detection and Quantification of Environmental Contamination. New York: John Wiley \& Sons, Inc.

GRANT, I.R., BALL, H.J., and ROWE, M.T. (1998). Isolation of Mycobacterium paratuberculosis from milk by immunomagnetic separation. Appl. Environ. Microbiol. 64, 3153.

GRUDEN, C.L., SKERLOS, S.J., and ADRIAENS, P. (2004). Flow cytometry for microbial sensing in environmental sustainability applications: current status and future prospects. FEMS Microbiol. Ecol. 49, 37.

HABBERSETT, M.C., SHAPIRO, M., BUNNAG, B., NISHIYA, I., and HERMAN, C. (1979). Quantitative analysis of flow microfluorometric data for screening gynecologic cytology specimens. J. Histochem. Cytochem. 27, 536.

HARRISON, S.T.L. (1991). Bacterial cell disruption: A key unit operation in the recovery of intracellular products. Biotechnol. Adv. 9, 217.

HAYWARD-FARMER, E., and OTTO, S.P. (2003). The evolution of genomic base composition in bacteria. Evolution $\mathbf{5 7}$, 1783.

HILL, E.C. (1977). Microbial infection of cutting fluids. Tribol. Int. 49.

HUANG, S.H., LIAO, M.H., and CHEN, D.H. (2003). Direct binding and chracterization of lipase onto nanopartilces. Biotechnol. Prog, 19, 1095.

INDEPENDENT LUBRICANT MANUFACTURE ASSOCIATION. (2000). ILMA Report. Lubricants World, 10.

KEPNER, R.L., JR. and PRATT, J.R. (1994). Use of fluorochromes for direct enumeration of total bacteria in environmental samples: Past and present. Microbiol. Rev. 58, 603.

KHAN, I.U.H., and YADAV, J.S. (2004a). Development of a single-tube, cell lysis-based, genus-specific PCR method for rapid identification of mycobacteria: Optimization of cell lysis, per primers and conditions, and restriction pattern analysis. J. Clin. Microbiol. 42, 453.

KHAN, I.U.H., and YADAV, J.S. (2004b). Real-time PCR assay for genus-specific detection and quantification of culturable and non-culturable mycaobacteria and pseudomonads in metalworking fluids. Mol. Cell. Probes 18, 67.

KOLMOGOROV, A.N. (1933). Sulla deteminazioneemprica di una legge di distrbuzione (English translation can be found in: Kolmogorov, A. 1950. Foundations of the Theory of Probability. New York: Chelsea). Giornale dell' Instuto Itlanio Dlgi Attuari 3, 77.

KONERACHÁ, M., KOPANSKÝ, P., TIMBO, M., RAMCHAND, C.N., DE SEQUEIRA, A., and TREVAN, M. (2002). Direct binding procedure of proteins and enzymes to fine magnetic particles. J. Mol. Catal. B: Enzymatics 18, 13. 
KREISS, K., and COX-GANSER, J. (1997). Metalworking fluid-associated hypersensitivity pneumonitis a workshop summary. Am. J. Indust. Med. 32, 423.

KUSUNOKI, H., BARI, M.L., KITA, T., SUGII, S., and UEMURA, T. (2000). Flow cytometry for the detection of enterohaemorrhagic Escherichia coli O157: H7 with latex beads sensitized with specific antibody. J. Vet. Med. Series B-Infect. Dis. Vet. Public Health 47, 551.

LAMPAREILLO, F. (2000). On the use of the KolmogorovSmirnov statistical test for immunofluorescence histogram comparison. Cytometry 39, 179.

LIU, Y., CHE, Y., and LI, Y. (2001). Rapid detection of Salmonella typhimurium using immunomagnetic saparation and immuno-optical sensing method. Sensors Actuatoes B 72, 21.

LU, B., SMYTH, M.R., and O'KENNEDY, R. (1996). Immunological activities of IgG antibody on pre-coated Fc receptor surface. Anal. Chim. Acta 331, 97.

MADIGAN, M.T., MARTINKO, J.M., and PRAKER, J. (2003). Biology of Microorganisms. 10th ed. Upper Saddle River, NJ: Pearson Education, Inc.

MAZUREK, G.H., LOBUE, P.A., DALEY, C.L., BERNARDO, J., LARDIZABAL, A.A., BISHAI, W.R., IADEMARCO, M.F., and ROTHEL, J.S. (2001). Comparison of whole-blood interferon assay with tuberclin skin testing for detecting latent Mycobacterium tuberculosis infection. J. Am. Med. Assoc. 286, 1740.

MCCLELLAND, R.G., and PINDER, A.C. (1994). Detection of Salmonella typhimurium in dairy products with flow cytometry and monoclonal antibody. Appl. Environ. Microbiol. 60, 4255 .

MEHTA, R.V., UPADHYAY, R.V., CHARLES, S.W., and RAMCHAND, C.N. (1997). Direct binding of protein to magnetic particles. Biotechnol. Techniques 11, 493.

MELNIKOVA, Y.A.I., ODINTSOV, S.G., KRAKCHUNK, Z.I., and MARTSEV, S.P. (2000). Antigen-binding activity of monoclonal antibodies after incubation with organic solvents. Biochemistry (Moscow) 65, 1256.

MILTENYI, S., MULLER, W., WEICHEL, W., and RADBRUCH, A. (1990). High-gradient magnetic cell-separation with MACS. Cytometry 11, 231.

MIROLIAEI, M., and NAMAT-GORGANI, M. (2002). Effects of organic solvents on stability and activity of two related alcohol dehydrogenases: A comparative study. Int. J. Biochem. Cell Biol. 34, 169.

MOORE, J.S., CHRISTENSEN, M., and WILSON, R.W. (2000). Mycobacterial contamination of metalworking fluids: Involvement of a possible new taxon of rapidly growing mycobacteria. Am. Indust. Hygiene Assoc. J. 61, 205.

MUILENBERG, M.L., BURGE, H.A., and SWEET, T. (1993). Hypersensitivity pneumonitis and exposure to acid-fast bacilli in coolant aerosols. J. Allergy Clin. Immunol. 91, 311.
MURPHY, R.F. (1985). Automated identification of subpopulation in flow cytometric list mode data using cluster analysis. Cytometry 6, 302.

NEBE-VON-CARON, G., STEPHENS, P.J., HEWITT, C.J., POWELL, J.R., and BADLEY, R.A. (2000). Analysis of bacterial function by multi-colour fluorescence flow cytometry and single cell sorting. J. Microbiol. Methods 42, 97.

NGUYEN, D., DIAMOND, L.W., and BRAYLAN, R.C. (2003). Flow cytometry in hematopathology: A visual approach to data analysis and interpretation. New Jersey: Humana Press.

ORTALO-MAGNÉ, A., LEMASSU, A., LANÉELLE, M.A., BARDOU, F., SILVE, G., GOUNON, P., MARCHAL, G., and DAFFÉ, M. (1996). Identification of the surface-exposed lipids on the cell envelopes of Mycobacterium tuberculosis and other mycobacterial species. J. Bacteriol. 178, 456.

PARIKH, H.H., LI, W.C., and RAMANATHAN, M. (1999). Evaluation of an alternative to the Kolmogorov-Simirnov test for flow cytometric histogram comparisons. J. Immunol. Methods 229, 97.

PASSMAN, F.J., and ROSSMOORE, H.W. (2002). Reassessing the health risks associated with employee exposure to metalworking fluid microbes. Lubricat. Eng. 58, 30.

PORTER, J. (1999). Specific detection, viability assessment and macromolecular staining of bacteria for flow cytometry. In Edwards, C., Ed., Environmental Monitoring of Bacteria; New Jersey: Humana Press Inc.

PORTER, J., DEERE, D., HARDMAN, M., EDWARDS, C., and PICKUP, R. (1997). Go with the flow-Use of flow cytometry in environmental microbiology. FEMS Microbiol. Ecol. 24, 93.

ROBERTS, B., and HIRST, R. (1997). Immunomagnetic separation and PCR for detection of Mycobacterium ulcerns. $\underline{\text { J. }}$ Clin. Microbiol. 35, 2709.

ROMESBURG, H.C. (1984). Cluster Analysis for Researchers. North Carolina: Lulu Press.

ŠAFAŘÍK, I., and ŠAFAŘíKOVÁ, M. (1999). Use of magnetic techniques for isolation of cells. J. Chromatogr. B 722, 33.

SALZMAN, G.C. , HIEBERT, R.D., and CROWELL, J.M. (1978). Data acquisition and display for a high-speed cell sorter. Comput. Biomed. Res. 11, 77.

SCHUT, T.C.B., DE GOOTH, B.G., and GREVE, J. (1993). Cluster analysis of flow cytometric list mode data on a personal computer. Cytometry 14, 649.

SEO, K.H., BRACKETT, R.E., and FRANK, J.F. (1998). Rapid detection of Echerichia coli O157:H7 using immunomagnetic flow cytometry in ground beef, apple juice, and milk. Int. J. Food Microbiol. 44, 115.

SHELTON, B.G., FLANDERS, W.D., and MORRIS, G.K. (1999). Mycobacterium sp. as a possible cause of hypersensitivity pneumonitis in machine workers. Emerging Infect. Dis. 5, 270. 
SHINKAI, M., WANG, J., KAMIHIRA, M., IWATA, M., HONDA, H., and KOBAYASHI, T. (1992). Rapid enzymelinked immunosorbent assay with functional magnetite particle. J. Ferment. Bioeng. 73, 166.

SKERLOS, S.J., SKERLOS, L.A., AGUILAR, C.A., and ZHAO, F. (2003). Expeditious identification and quantification of mycobacteria species in metalworking fluids using peptide nucleic acids. J. Manufact. Syst. 22, 137.

STÖHR, M., and FUTTERMAN, G. (1979). Visualization of multidimensional spectra in flow cytometry. J. Histochem. Cytochem. 27, 560.

TSO, S.F., and TAGHON, G. L. (1997). Enumeration of protozoa and bacteria in muddy sediment. Microbial Ecol. 33, 144.

TURKOVÁ, J. (1999). Oriented immobilization of biologically active proteins as a tool for revealing protein interactions and function. J. Chromatogr. $B$ 722, 11 .

VAN DER GAST, C.J., KNOWLES, C.J., WRIGHT, M.A., and THOMPSON, I.P. (2001). Identification and characterization of bacterial populations of an in-use metalworking fluid by phenotypic and genotypic methodology. Int. Biodeteriorat. Biodegrad. 47, 113.

VEAL, D.A., DEERE, D., FERRARO, B., PIPER, J., and ATTFIELD, P.V. (2000). Fluorescence staining and flow cytometry for monitoring microbial cells. J. Immunol. Methods 243, 191.

VEILlETTE, M., THORNE, P.S., GORDON, T., and DUCHAINE, C. (2004). Six month tracking of microbial growth in a metalworking fluid after system cleaning and recharging. Ann. Occupat. Hygiene 48, 541.

VIVES-REGO, J., LEBARON, P., and NEBE-VON-CARON, G. (2000). Current and future applications of flow cytometry in aquatic microbiology. FEMS Microbiol. Rev. 24, 429.

WALLACE, R.J., JR., ZHANG, Y., WILSON, R., MANN, L., and ROSSMOORE, H.W. (2002). Presence of a single genotype of the newly described species Mycobacterium immunogenum in industrial metalworking fluids associated with hypersensitivity pneumonitis. Appl. Environ. Microbiol. 68, 5580.

WEETALL, H.H. (1992). Preparation of immobilized proteins covalently coupled through silane coupling agents to inorganic supports. In The Proceedings of the Mosbach Sympo- sium on Biochemical Technology, December 2-4, 1992, Lund, Sweden.

WEETALL, H.H. (1976). Covalent coupling methods for inorganic supports. Enzymol. 44, 134.

WEISS, L., PUE, C., ROSSMOORE, H.W., FINK, J., HARNEY, J., and TROUT, D. (2001). Respiratory illness in workers exposed to metalworking fluid contaminated with nontuberculous Mycobacteria-Ohio, 2001. JAMA 287, 3073.

WILSON, R.W., STEINGRUBE, V.A., BOTTGER, E.C., SPRINGER, B., BROWN-ELLIOTT, B.A., VINCENT, V., JOST, K.C., JR, ZHANG, Y., GARCIA, M.J., CHIU, S.H., et al. (2001). Mycobacterium immunogenum sp., a novel species related to Mycobacterium abscessus and associated with clinical disease, pseudo-outbreaks and contaminated metalworking fluids: an international cooperative study on mycobacterial taxonomy. Int. J. Syst. Evol. Microbiol. 51, 1751.

XU, Y., MCKENNA, R.W., and KRIFT, S.H. (2002). Comparison of multiparameter flow cytometry with cluster analysis and immunohistochemistry for detection of CD10 in diffuse large B-cell lymphomas. Modern Pathol. 15, 413.

YADAV, J.S., KHAN, I.U.H., FAKHARI, F., and SOELLNER, M.B. (2003). DNA-based methodologies for rapid detection, quantification, and species- or strain-level identification of respiratory pathogens (Mycobacteria and Pseudomonads) in metalworking fluids. Appl. Occupat. Environ. Hygiene 18, 966.

YEN, Y.C. (1992). Nonparametric Statistics. Taipei, Taiwan: National Taiwan University Press.

YI, W.C., HSIAO, S., LIU, J.H., SOO, P.C., HORNG, Y.T., TSAI, W.C., LAI, H.C., TENG, L.J., HSUEH, P.R., HSIEH, R.F., et al. (1998). Use of fluorescein labeled antibody and fluorescence activated cell sorter for rapid identification of Mycobacterium species. Biochem. Biophys. Res. Commun. 250, 403.

YOUNG, I.T. (1977). Proof without prejudice: use of the Kolmogorov-Smirnov test for the analysis of histograms from flow systems and other sources. J. Histochem. Cytochem. 25, 935.

ZHANG, Y., KOHLER, N., and ZHANG, M. (2002). Surface modification of superparamagnetic magnetite nanoparticles and their intracellular uptake. Biomaterials 23, 1553. 